\title{
Serum Nitric Oxide as a Predictive Biomarker for Bevacizumab in Non-small Cell Lung Cancer Patients
}

\author{
SATOSHI MUTO, HIRONORI TAKAGI, YUKI OWADA, TAKUYA INOUE, YUZURU WATANABE, \\ TAKUMI YAMAURA, MITSURO FUKUHARA, NAOYUKI OKABE, YUKI MATSUMURA, TAKEO HASEGAWA, \\ JUN OSUGI, MIKA HOSHINO, MITSUNORI HIGUCHI, YUTAKA SHIO and HIROYUKI SUZUKI \\ Department of Chest Surgery, Fukushima Medical University School of Medicine, Fukushima, Japan
}

\begin{abstract}
Background/Aim: Reportedly, hypertension tends to be associated with response to bevacizumab therapy, because bevacizumab suppresses vascular nitric oxide production. In this study we examined the predictive value of nitric oxide in bevacizumab-treated non-small cell lung cancer (NSCLC) patients. Patients and Methods: Fifteen patients with advanced or recurrent NSCLC treated with bevacizumab-based regimens were evaluated retrospectively. Serum $\mathrm{NOx}\left(\mathrm{NO}_{2}{ }^{-} / \mathrm{NO}_{3}^{-}\right)$was assayed by the Griess method. Results: Serum nitric oxide levels were decreased after two courses of bevacizumab treatment in our responder group $(p=0.02)$. According to the change in nitric oxide levels after the second course of treatment, median progression-free survival was 11.0 months in the group with decreased serum nitric oxide and 7.6 months in the group with increased serum nitric oxide $(p=0.08)$. Conclusion: Serum nitric oxide levels could be a predictive biomarker for response to bevacizumab in NSCLC patients.
\end{abstract}

Lung cancer is the leading cause of cancer death worldwide (1). Significant survival improvement has been achieved in recent years in patients with lung adenocarcinoma, much of which has been attained by advances in molecular-targeted agents.

Bevacizumab is a recombinant humanized monoclonal antibody for vascular endothelial growth factor (VEGF). Anti-VEGF antibody exerts its effect by inhibiting tumor angiogenesis $(2,3)$. For untreated advanced or recurrent non-

Correspondence to: Satoshi Muto, Department of Chest Surgery, Fukushima Medical University School of Medicine, 1 Hikarigaoka, Fukushima 960-1295, Japan. Tel: +81-24-548-2111, Fax: +81-24548-2735, e-mail: smutoo@fmu.ac.jp

Key Words: Non-small cell lung cancer, bevacizumab, nitric oxide, biomarker. squamous NSCLC patients, standard chemotherapy plus bevacizumab treatment resulted in a median progression-free survival (PFS) rate of 6.2-7.4 months (4-7). Besides NSCLC, bevacizumab is also effective against colorectal cancer (8), ovarian cancer (9), cervical cancer (10), and glioblastoma (11). On the other hand, the FDA has removed bevacizumab as a treatment for breast cancer because of its minimal effect on tumor growth without evidence of a longer life span (12). The clinical benefits associated with the use of bevacizumab have, so far, been limited. One of the reasons is that there are not enough predictive biomarkers that can distinguish its effectiveness in patients (13). Hypertension, imaging, infiltrating myeloid cells, circulating biomarkers, polymorphisms in the VEGF pathways and in situ biomarkers have been studied for predictive biomarkers of bevacizumab (14-17). However, no definitive biomarkers have been identified.

Regarding these points, many studies on hypertension have been performed. Some clinicians have reported that bevacizumab had a greater effect in patients with hypertension as an adverse event in NSCLC (18), colon cancer (19) and breast cancer (20). Although these results suggest the capability of early hypertension as a predictive biomarker (21), there was no significant difference with or without early hypertension in meta-analysis (22).

In this study we focused on nitric oxide instead of hypertension itself. Bevacizumab sometimes increases blood pressure via nitric oxide (23). Administration of bevacizumab decreased serum nitric oxide in animal models (24), and it is thought that nitric oxide is associated with the mechanism of action of bevacizumab (25).

We, thus, studied the relationship between the changes in serum nitric oxide levels before and after bevacizumab administration and the treatment effects on patients with advanced or recurrent NSCLC (non-squamous) who had been administered chemotherapy plus bevacizumab. We also report the association between hypertension and serum nitric oxide levels or treatment efficacy. 


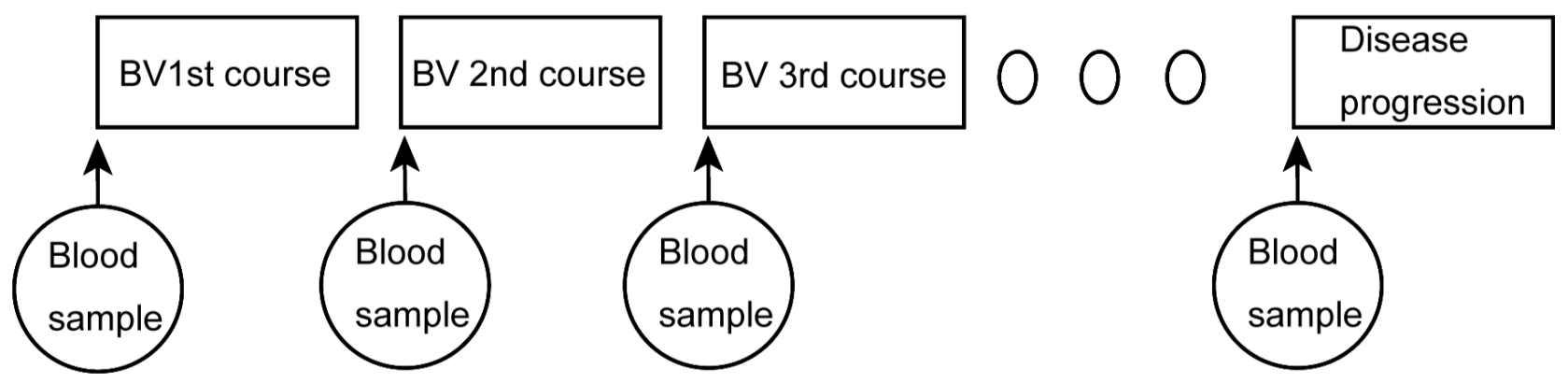

Figure 1. Bevacizumab treatment and blood sampling procedure. Blood samples were obtained prior to the start of bevacizumab treatment, after the first course of treatment, after the second course of treatment, and after disease progression.

\section{Patients and Methods}

Patients. We retrospectively enrolled 15 patients with recurrent NSCLC who underwent treatment with bevacizumab between January 2010 and October 2013 at the Fukushima Medical University hospital. The main inclusion criteria were as follows: aged over 20 years old, diagnosed with recurrent NSCLC, Eastern cooperative oncology group (ECOG) Performance status (PS) under stage 3 , and no contraindication for bevacizumab combination chemotherapy. This study was approved by the Ethics Committee of Fukushima Medical University (No. 1594). Written informed consents were also obtained from all patients.

Samples and evaluation. Blood samples were obtained on four occasions from each patient: before the start of bevacizumab combination chemotherapy, after the first course, after the second course, and after disease progression (Figure 1). These samples were used to investigate serum nitric oxide levels. Serum levels of nitric oxide were determined by the Griess Method at FALCO Biosystems Ltd. (Kyoto, Japan). This method can determine $\mathrm{NO}_{2}{ }^{-}$and $\mathrm{NO}_{3}{ }^{-}$. Since most of the nitric oxide is oxidized to $\mathrm{NO}_{2}{ }^{-}$and $\mathrm{NO}_{3}{ }^{-}$, the concentrations of these anions are used as a quantitative measure of nitric oxide production. We assessed the objective response according to the new response evaluation criteria in solid tumors (RECIST) guidelines (version 1.1). The interval of CT evaluation was not defined beforehand and was performed within the standard of care. Common Terminology Criteria for Adverse Events (CTCAE) v4.0 was used to evaluate adverse events including hypertension.

Statistical analysis. We analysed the relationship between serum nitric oxide levels and clinical response or hypertension. We compared PFS or hypertension according to nitric oxide decrease. All analyses were performed using GraphPad Prism 5 software (GraphPad Software Inc. La Jolla, CA, USA). Continuous measurements were expressed as mean \pm standard deviation. Comparison between groups of continuous measurements was performed using the paired Student's $t$-test. Survival curves were drawn according to the Kaplan-Meier method. We compared PFS between groups using the Log-rank test. $p$-Values of $<0.05$ were considered to be statistically significant.

\section{Results}

Patient characteristics and clinical benefit. Of the 15 patients, six (40\%) were male and the mean age was $65.3 \pm 6.3$ years (range, 55-74). All patients had recurrent lung adenocarcinoma. Six patients $(40 \%)$ had an epidermal growth factor receptor (EGFR) mutation-positive tumor. Recurrent lesions of the lung were found in $12(80 \%)$ patients, pleura in one $(7 \%)$, adrenal gland and mediastinal lymph node in one $(7 \%)$, and bone and liver in one $(7 \%)$. Bevacizumab combination therapy was administered as the first-line chemotherapy in five $(33 \%)$ patients, second-line chemotherapy in six $(40 \%)$, and third-line or more in four $(27 \%)$. A combined regimen of cisplatin plus pemetrexed was administered to $11(73 \%)$ patients, carboplatin plus pemetrexed to three $(20 \%)$, and carboplatin + paclitaxel to one $(7 \%)$. Six $(40 \%)$ patients underwent maintenance therapy, with bevacizumab administered to five (33\%) patients, and pemetrexed to one $(7 \%)$. Patient characteristics are summarized in Table I.

One patient exhibited a complete response, seven had a partial response, four had stable disease, and three experienced disease progression in this treatment period. The response rate was $53.3 \%$ and the disease control rate was $80.0 \%$. Median PFS was $11.1 \pm 7.7$ months. Hypertension was observed as an adverse event in nine patients $(60 \%)$. One patient had grade 1 hypertension, two had grade 2 and six had grade 3 .

Serum nitric oxide and clinical response. Changes in serum nitric oxide levels in responders and non-responders are shown in Figure 2. In the responder group, serum nitric oxide level was $69.0 \pm 40.2 \mu \mathrm{mol} / \mathrm{l}$ before treatment, $46.1 \pm 36.0 \mu \mathrm{mol} / \mathrm{l}$ after the first course of treatment, and $28.1 \pm 22.9 \mu \mathrm{mol} / 1$ after the second. There was a significant decrease between serum nitric oxide levels before treatment and after the second course 

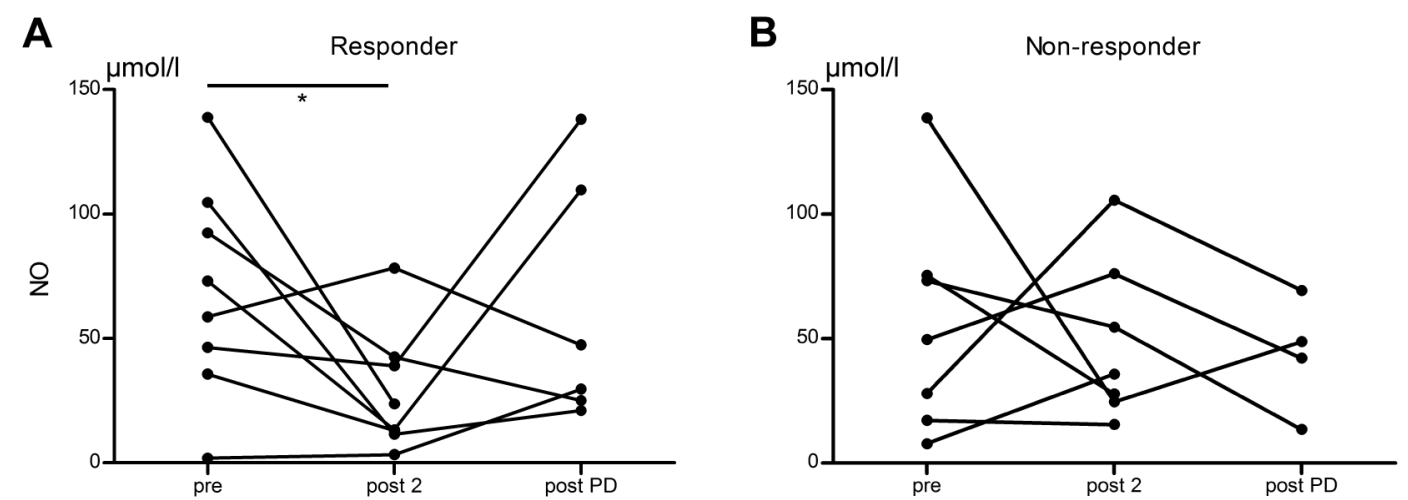

Figure 2. Serum nitric oxide levels and response. (A) Responders and (B) non-responders. There was a significant decrease between serum nitric oxide levels before treatment and after the second course in responders. NO: nitric oxide; pre: before treatment; post 2: after second course of treatment; post PD: after disease progression; $* p<0.05$.

$(p=0.02)$; although, there was no significant difference between levels before treatment and after the first course. After disease progression, the serum nitric oxide level was $61.8 \pm 45.4 \mu \mathrm{mol} / 1$. No significant increase was detected during the period between the second course of treatment and after disease progression (Figure 2A).

In the non-responder group, serum nitric oxide level was $55.6 \pm 41.7 \mu \mathrm{mol} / \mathrm{l}$ before treatment, $47.1 \pm 20.3 \mu \mathrm{mol} / \mathrm{l}$ after the first course of treatment, $48.5 \pm 30.0 \mu \mathrm{mol} / 1$ after the second course, and 43.4 $\pm 20.0 \mu \mathrm{mol} / 1$ after disease progression. There was no significant difference in the level of nitric oxide in the non-responder group (Figure 2B). Moreover, there was no significant difference in nitric oxide levels before treatment between the responder and nonresponder groups $(p=0.57)$.

Serum nitric oxide and hypertension. Regarding the relationship of hypertension as an adverse event, serum nitric oxide levels are shown in Figure 3. In the hypertension group, serum nitric oxide level was $75.9 \pm 44.3 \mu \mathrm{mol} / \mathrm{l}$ before treatment, $47.5 \pm 21.8 \mu \mathrm{mol} / \mathrm{l}$ after the first course of treatment, $29.0 \pm 20.5 \mu \mathrm{mol} / \mathrm{l}$ after the second course, and 50.8 \pm 40.2 $\mu \mathrm{mol} / \mathrm{l}$ after disease progression (Figure $3 \mathrm{~A}$ ). In the nonhypertension group, serum nitric oxide level was $42.9 \pm 26.5$ $\mu \mathrm{mol} / \mathrm{l}$ before treatment, $45.2 \pm 38.6 \mu \mathrm{mol} / 1$ after the first course of treatment, $50.5 \pm 33.3 \mu \mathrm{mol} / 1$ after the second course, and $60.0 \pm 35.0 \mu \mathrm{mol} / 1$ after disease progression (Figure $3 \mathrm{~B}$ ). Serum nitric oxide levels were significantly decreased after the second course of treatment in the hypertension group $(p=0.006)$. Any other significant differences were not demonstrated in either group. There was no significant difference in nitric oxide levels before treatment dependent on the presence or absence of hypertension; however, it tended to be higher in the hypertension group.
Table I. Patient characteristics.

\begin{tabular}{lc}
\hline Characteristics & N $(\%)$ \\
\hline Age (years) & \\
Mean \pm SD & $65.3 \pm 6.3$ \\
Gender & \\
Female & $9(60)$ \\
Male & $6(40)$ \\
Histology & \\
Adenocarcinoma & $15(100)$ \\
EGFR mutation & \\
Positive & $6(40)$ \\
Negative & $9(60)$ \\
Site of recurrence & \\
Lung & $12(80)$ \\
Pleura & $1(7)$ \\
Adrenal gland and Lymph node & $1(7)$ \\
Bone and Liver & $1(7)$ \\
Chemotherapy & \\
1st line & $5(33)$ \\
2nd line & $6(40)$ \\
3rd line- & $4(27)$ \\
Regimen & \\
CDDP + PEM + BV & $11(73)$ \\
CBDCA + PEM + BV & $3(20)$ \\
CBDCA + PTX + BV & $1(7)$ \\
Maintenance & \\
BV & $5(33)$ \\
PEM & $1(7)$ \\
None & $9(60)$ \\
\hline
\end{tabular}

EGFR: Epidermal growth factor receptor; CDDP: cisplatin; PEM: pemetrexed; BV: bevacizumab; CBDCA: carboplatin; PTX: paclitaxel.

Serum nitric oxide and progression-free survival. The relationship between PFS, nitric oxide decrease, and hypertension is demonstrated in Figure 4. According to nitric oxide level changes after the second course of treatment, the 
A

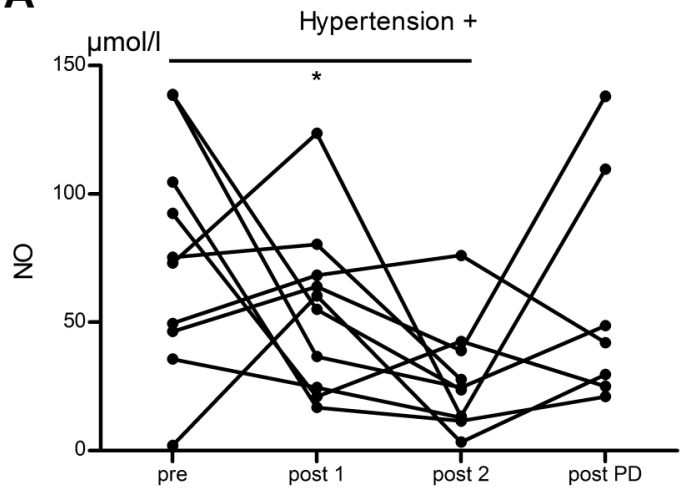

B

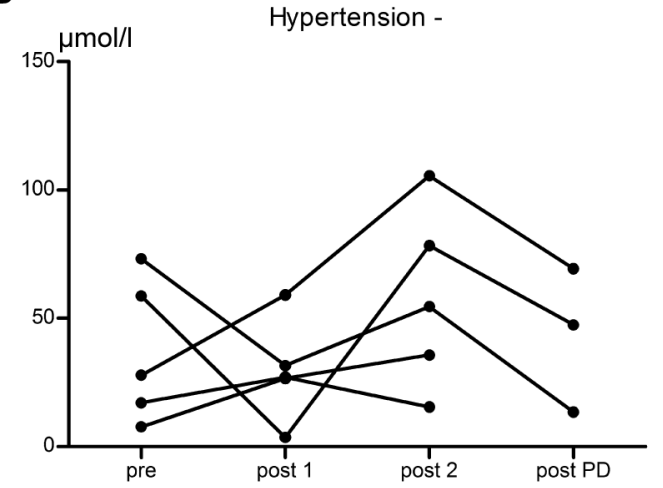

Figure 3. Serum nitric oxide levels and hypertension. (A) With hypertension and (B) without hypertension. Serum nitric oxide levels were significantly decreased after the second course of treatment in the hypertension group. NO: Nitric oxide; pre: before treatment; post 1: after first course of treatment; post 2: after second course of treatment; post PD: after disease progression; ${ }^{*} p<0.05$.

A

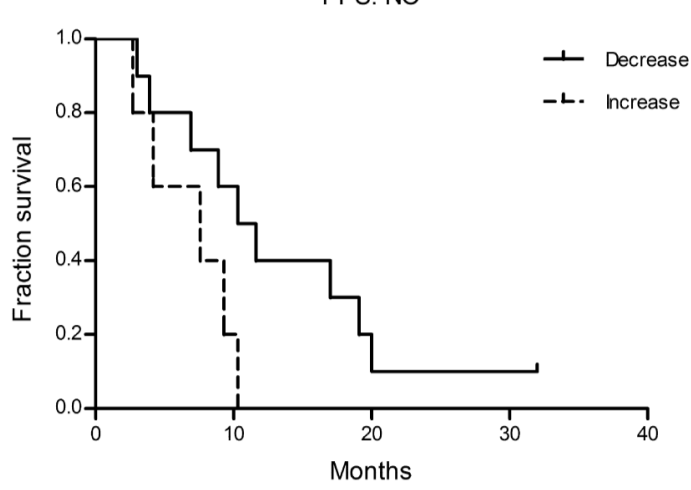

B

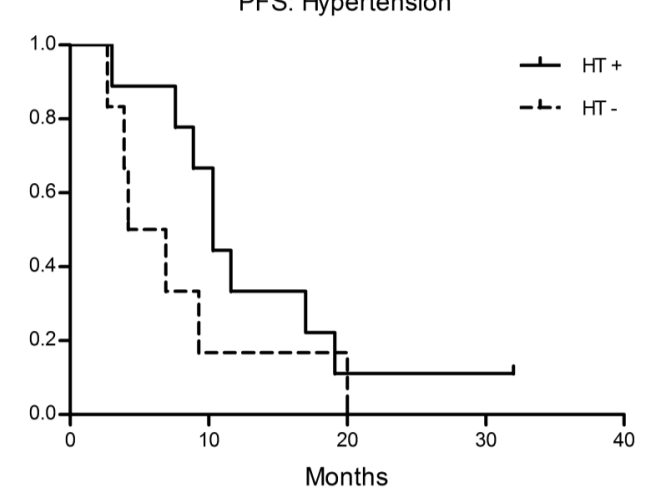

Figure 4. Progression-free survival curve of patients. (A) Decrease or increase in serum nitric oxide levels after the second course of bevacizumab treatment, (B) with or without hypertension as an adverse event. PFS tended to be longer in the group with decreased nitric oxide levels, although not significant $(p=0.08)$.

median PFS was 11.0 months in the group with decreased levels and 7.6 months in the group with increased levels ( $p=0.08$; Figure 4A). Regarding hypertension as an adverse event, the median PFS was 10.3 months in the hypertension group and 5.6 months in the non-hypertension group $(p=0.21$; Figure 4B).

\section{Discussion}

We studied the changes in serum nitric oxide levels before and after the administration of chemotherapy plus bevacizumab in patients with NSCLC. This study revealed that serum nitric oxide levels were decreased after two courses of treatment. This is the first analysis of serum nitric oxide during bevacizumab-containing chemotherapy in NSCLC patients.
Although serum VEGF, and matrix metalloproteinase-9 levels were previously studied as circulating biomarkers of bevacizumab response in patients with NSCLC, no significant impact was identified (17). Serum nitric oxide has been examined in patients with colon cancer and no significant change before and after bevacizumab treatment was found (26); however, serum nitric oxide levels were evaluated after six courses of treatment. We speculated that serum nitric oxide levels increased again after six courses, even in patients with decreased nitric oxide levels after two courses.

With regards to bevacizumab beyond disease progression after first-line treatment with chemotherapy plus bevacizumab in NSCLC, there are few reports. Takeda et al. reported that continuation of bevacizumab beyond disease progression showed longer PFS in a phase II trial (27). Furthermore, a 
phase III trial (NCT01351415) is now ongoing (28). However, these trials are intended for all NSCLC patients who had experienced failure in first-line treatments. It is desirable to distinguish patients who can obtain benefit from bevacizumab, therefore we focused on the role of serum nitric oxide as a marker for bevacizumab response.

Changes in serum nitric oxide before and after bevacizumab treatment differed between the responder and non-responder groups in this study. The responder group exhibited a significant decrease in serum nitric oxide after two courses of treatment (Figure 2). Those with decreased nitric oxide levels after two courses of treatment also tended to have longer PFS. Although we could not detect the statistical significance (Figure 4A), we think it is because the number of patient in this study was small. Thus, the change in levels after two courses of treatment may be a useful biomarker. A study using a larger population needs to be conducted to confirm this finding.

In addition, attention should be paid to the changes in serum nitric oxide levels after disease progression. Some responders showed an increase in serum nitric oxide, but others maintained low levels after disease progression (Figure 2). We considered that these patients still have the chance of clinical benefit from bevacizumab even after disease progression. We may have to continue the administration of bevacizumab during the next treatment regimen for these patients. This study suggested the possibility that treatment with bevacizumab beyond disease progression is more effective in patients with decreased levels of serum nitric oxide. Although it is difficult to design a prospective randomized study for nitric oxide, it is worth examining it. Both VEGF antibody and its receptor antibody have obtained recent approval (29). Serum nitric oxide may be a useful biomarker when determining subsequent treatment regimens after disease progression.

It is thought that a decrease in serum nitric oxide induces hypertension as an adverse event of bevacizumab treatment (25). Patients who exhibited hypertension as an adverse event of bevacizumab showed a decrease in serum nitric levels after two courses of treatment (Figure 3). This result confirms that nitric oxide is associated with hypertension. However, it is not known exactly when hypertension occurs. It was concluded from seven phase III studies that early hypertension does not predict clinical benefit for bevacizumab (22).

Finally, we would like to review the clinical results of this study. It has been reported that bevacizumab in combination with standard chemotherapy showed a $30.4-60.7 \%$ objective response and median PFS of 6.2-7.4 months (4-7). In this study, the objective response was $53.3 \%$, comparable to the results of previous studies. The median PFS was 11.1 months in this study, and thus longer than previous studies. This result may be because this study was retrospective in a real- world setting, so the evaluation interval was longer than that in previous clinical trials. The retrospective design may have also caused a high incidence of hypertension as an adverse event. It is difficult to prevent observer bias in a retrospective study.

Our data suggest that changes in serum nitric oxide levels before bevacizumab administration and after two courses of treatment could predict its therapeutic effects. Moreover, serum nitric oxide levels after disease progression could be a useful biomarker for determining whether anti-VEGF therapy should be continued. However, further prospective confirmation is needed.

\section{Acknowledgements}

The Authors would like to thank E. Ohtomo, Y. Kikuta, Y. Kimura, and $\mathrm{H}$. I for their technical assistance. This study was supported in part by Chugai Pharmaceutical Co., Ltd. (Tokyo, Japan).

\section{References}

1 Siegel R, Ma J, Zou Z and Jemal A: Cancer statistics, 2014. CA Cancer J Clin 64: 9-29, 2014.

2 Folkman J: Tumor angiogenesis: therapeutic implications. N Engl J Med 285: 1182-1186, 1971.

3 Bergers $\mathrm{G}$ and Benjamin LE: Tumorigenesis and the angiogenic switch. Nat Rev Cancer 3: 401-10, 2003.

4 Niho S, Kunitoh H, Nokihara H, Horai T, Ichinose Y, Hida T, Yamamoto N, Kawahara M, Shinkai T, Nakagawa K, Matsui K, Negoro S, Yokoyama A, Kudoh S, Kiura K, Mori K, Okamoto H, Sakai H, Takeda K, Yokota S, Saijo N and Fukuoka M: Randomized phase II study of first-line carboplatin-paclitaxel with or without bevacizumab in Japanese patients with advanced non-squamous non-small-cell lung cancer. Lung Cancer 76: $362-$ 367, 2012.

5 Sandler A, Gray R, Perry MC, Brahmer J, Schiller JH, Dowlati A, Lilenbaum R and Johnson DH: Paclitaxel-carboplatin alone or with bevacizumab for non-small-cell lung cancer. N Engl J Med 355: 2542-2550, 2006.

6 Reck M, von Pawel J, Zatloukal P, Ramlau R, Gorbounova V, Hirsh V, Leighl N, Mezger J, Archer V, Moore N and Manegold C: Overall survival with cisplatin-gemcitabine and bevacizumab or placebo as first-line therapy for nonsquamous non-small-cell lung cancer: results from a randomised phase III trial (AVAiL). Ann Oncol 21: 1804-1809, 2010.

7 Johnson DH, Fehrenbacher L, Novotny WF, Herbst RS, Nemunaitis JJ, Jablons DM, Langer CJ, DeVore RF 3rd, Gaudreault J, Damico LA, Holmgren E and Kabbinavar F: Randomized phase II trial comparing bevacizumab plus carboplatin and paclitaxel with carboplatin and paclitaxel alone in previously untreated locally advanced or metastatic nonsmall-cell lung cancer. J Clin Oncol 22: 2184-2191, 2004.

8 Saltz LB, Clarke S, Diaz-Rubio E, Scheithauer W, Figer A, Wong R, Koski S, Lichinitser M, Yang TS, Rivera F, Couture F, Sirzen F and Cassidy J: Bevacizumab in combination with oxaliplatin-based chemotherapy as first-line therapy in metastatic colorectal cancer: a randomized phase III study. J Clin Oncol 26: 2013-2019, 2008. 
9 Burger RA, Brady MF, Bookman MA, Fleming GF, Monk BJ, Huang H, Mannel RS, Homesley HD, Fowler J, Greer BE, Boente M, Birrer MJ and Liang SX: Incorporation of Bevacizumab in the Primary Treatment of Ovarian Cancer. N Engl J Med 365: 2473-2483, 2011.

10 Tewari KS, Sill MW, Long HJ, 3rd, Penson RT, Huang H, Ramondetta LM, Landrum LM, Oaknin A, Reid TJ, Leitao MM, Michael HE and Monk BJ: Improved survival with bevacizumab in advanced cervical cancer. N Engl J Med 370: 734-743, 2014.

11 Chinot OL, Wick W, Mason W, Henriksson R, Saran F, Nishikawa R, Carpentier AF, Hoang-Xuan K, Kavan P, Cernea $\mathrm{D}$, Brandes AA, Hilton $\mathrm{M}$, Abrey $\mathrm{L}$ and Cloughesy $\mathrm{T}$ : Bevacizumab plus Radiotherapy-Temozolomide for Newly Diagnosed Glioblastoma. N Engl J Med 370: 709-722, 2014

12 http://www.fda.gov/NewsEvents/Newsroom/PressAnnounce ments/ucm 279485.htm

13 Bertolini F, Marighetti P, Martin-Padura I, Mancuso P, Hu-Lowe DD, Shaked Y and D'Onofrio A: Anti-VEGF and beyond: shaping a new generation of anti-angiogenic therapies for cancer. Drug Discov Today 16: 1052-1060, 2011.

14 Jubb AM and Harris AL: Biomarkers to predict the clinical efficacy of bevacizumab in cancer. Lancet Oncol 11: 1172-1183, 2010.

15 Schneider BP, Shen F and Miller KD: Pharmacogenetic biomarkers for the prediction of response to antiangiogenic treatment. Lancet Oncol 13: e427-436, 2012.

16 Lambrechts D, Lenz HJ, de Haas S, Carmeliet P and Scherer SJ: Markers of response for the antiangiogenic agent bevacizumab. J Clin Oncol 31: 1219-1230, 2013.

17 Hiura K, Shiraishi A, Suzuki C, Takamura K, Yamamoto M, Komori H, Watanabe $\mathrm{Y}$ and Iwaki-Egawa S: MMP-9/ANC score as a predictive biomarker for efficacy of bevacizumab plus platinum doublet chemotherapy in patients with advanced or recurrent non-squamous non-small cell lung cancer. Cancer Biomarkers 15: 433-440, 2015.

18 Dahlberg SE, Sandler AB, Brahmer JR, Schiller JH and Johnson DH: Clinical course of advanced non-small-cell lung cancer patients experiencing hypertension during treatment with bevacizumab in combination with carboplatin and paclitaxel on ECOG 4599. J Clin Oncol 28: 949-954, 2010.

19 Cai J, Ma H, Huang F, Zhu D, Bi J, Ke Y and Zhang T: Correlation of bevacizumab-induced hypertension and outcomes of metastatic colorectal cancer patients treated with bevacizumab: a systematic review and meta-analysis. World J Surg Oncol 11: 306, 2013.

20 Gampenrieder SP, Romeder F, Muß C, Pircher M, Ressler S, Rinnerthaler G, Bartsch R, Sattlberger C, Mlineritsch B and Greil R: Hypertension as a predictive marker for bevacizumab in metastatic breast cancer: Results from a retrospective matched-pair analysis. Anticancer Res 34: 227-233, 2014.
21 Mir O, Coriat R, Cabanes L, Ropert S, Billemont B, Alexandre J, Durand JP, Treluyer JM, Knebelmann B and Goldwasser F: An observational study of bevacizumab-induced hypertension as a clinical biomarker of antitumor activity. Oncologist 16: 13251332,2011

22 Hurwitz HI, Douglas PS, Middleton JP, Sledge GW, Johnson DH, Reardon DA, Chen D and Rosen O: Analysis of early hypertension and clinical outcome with bevacizumab: results from seven phase III studies. Oncologist 18: 273-280, 2013.

23 Kruzliak P, Kovacova G and Pechanova O: Therapeutic potential of nitric oxide donors in the prevention and treatment of angiogenesis-inhibitor-induced hypertension. Angiogenesis 16: 289-295, 2013

24 Dinc E, Yildirim O, Ayaz L, Ozcan T and Yilmaz SN: Effects of intravitreal injection of bevacizumab on nitric oxide levels. Eye 29: 436-442, 2015

25 Thachil J: Nitric oxide and adverse events of vascular endothelial growth factor inhibitors. Curr Med Res Opin 27: 1503-1507, 2011.

26 Sumbul AT, Disel U, Sezgin N, Sezer A, Kose F, Besen AA, Sumbul Z, Abali $\mathrm{H}$ and Ozyilkan O: Can serial monitoring of serum Vascular Endothelial Growth Factor (VEGF), Nitric Oxide (NO), and Angiotensin II (ANGII) levels have predictive role during Bevacizumab treatment? Med Sci Monit 20: 428-433, 2014.

27 Takeda M, Yamanaka T, Seto T, Hayashi H, Azuma K, Okada M, Sugawara S, Daga H, Hirashima T, Yonesaka K, Urata Y, Murakami H, Saito H, Kubo A, Sawa T, Miyahara E, Nogami N, Nakagawa K, Nakanishi Y and Okamoto I: Bevacizumab beyond disease progression after first-line treatment with bevacizumab plus chemotherapy in advanced nonsquamous nonsmall cell lung cancer (West Japan Oncology Group 5910L): An open-label, randomized, phase 2 trial. Cancer 122: 1050-1059, 2016

28 Gridelli C, Bennouna J, de Castro J, Dingemans AM, Griesinger F, Grossi F, Rossi A, Thatcher N, Wong EK and Langer C: Randomized phase IIIb trial evaluating the continuation of bevacizumab beyond disease progression in patients with advanced non-squamous non-small-cell lung cancer after firstline treatment with bevacizumab plus platinum-based chemotherapy: treatment rationale and protocol dynamics of the AvaALL (MO22097) trial. Clin Lung Cancer 12: 407-411, 2011.

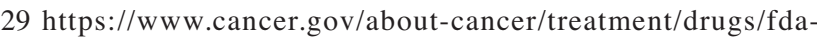
ramucirumab 